\title{
A Mutation in the Gene for Type III Procollagen (COL3A1) in a Family with Aortic Aneurysms
}

Sirpa Kontusaari, Gerard Tromp, Helena Kuivaniemi, Anne M. Romanic, and Darwin J. Prockop

Department of Biochemistry and Molecular Biology, Jefferson Institute of Molecular Medicine,

Jefferson Medical College, Thomas Jefferson University, Philadelphia, Pennsylvania 19107

\begin{abstract}
Experiments were carried out to test the hypothesis that familial aortic aneurysms, either thoracic or abdominal, are caused by mutations in the gene for type III procollagen (COL3A1) similar to mutations in the same gene that have been shown to cause rupture of aorta and other disastrous consequences in the rare genetic disorder known as Ehlers-Danlos syndrome type IV. A family was identified through a 37-yr-old female captain in the United States Air Force who was scrutinized only because many of her direct blood relatives had died of ruptured aortic aneurysms. The woman was heterozygous for a singlebase mutation that converted the codon for glycine 619 of the $\alpha 1$ (III) chain of type III procollagen to a codon for arginine. Studies on cultured skin fibroblasts demonstrated the mutation caused synthesis of type III procollagen that had a decreased temperature for thermal unfolding of the protein. The same mutation was identified in DNA extracted from pathologic specimens from her mother who had died at the age of 34 and a maternal aunt who died at the age of 55 of aortic aneurysms. Examination of DNA from samples of saliva revealed that the woman's daughter, her son, a brother, and an aunt also had the mutation. The results demonstrated that mutations in the type III procollagen gene can cause familial aortic aneurysms and that DNA tests for such mutations can identify individuals at risk for aneurysms. (J. Clin. Invest. 1990. 86:1465-1473.) Key words: mutation in type III procollagen • arterial aneurysms • DNA tests on saliva
\end{abstract}

\section{Introduction}

Rupture of aortic aneurysms is a common cause of death. In both the United Kingdom and in Sweden rupture of abdominal aortic aneurysms account for $\sim 1.3 \%$ of the deaths in men over $50 \mathrm{yr}$ of age $(1,2)$. Many aortic aneurysms are familial. For example, one recent report (3) demonstrated that $29 \%$ of asymptomatic brothers of patients with ruptured abdominal aortic aneurysms had dilatations of the aorta detectable by

Preliminary reports on this work have been published in abstract form (1989. Cytogenet. Cell Genet. 51:1024; 1990. Ann. NY Acad. Sci. 580:556-557; 1990. Clin. Res. 38:360A).

Address reprint requests to Dr. Darwin J. Prockop, Dept. of Biochemistry and Molecular Biology, Jefferson Institute of Molecular Medicine, Jefferson Medical College, Thomas Jefferson University, Philadelphia, PA 19107.

Received for publication 26 December 1989 and in revised form 1 May 1990.

J. Clin. Invest.

(c) The American Society for Clinical Investigation, Inc.

$0021-9738 / 90 / 11 / 1465 / 09 \$ 2.00$

Volume 86, November 1990, 1465-1473 ultrasound examination. Another recent report (4) indicated that $15.1 \%$ of 542 patients undergoing surgery for abdominal aortic aneurysms had a first-degree relative with an aneurysm. Therefore, although there may be a variety of causes for abdominal aortic aneurysms, a large proportion may be genetic. We have recently initiated experiments to test the hypothesis that familial aortic aneurysms, either thoracic or abdominal, are caused by mutations in the gene for type III procollagen (COL3A1) similar to mutations in the same gene that we and others (5-11) have shown to cause rupture of the aorta and other disastrous consequences in the rare genetic disorder known as Ehlers-Danlos syndrome (EDS) ${ }^{1}$ type IV (12-15). Here we show that the first family we used to test the hypothesis proved positive.

\section{Methods}

The family. The family was identified through a 37-yr-old white female (M.H.) on active duty as a captain in the United States Air Force (III-1 in Fig. 1). She was in excellent health and physical condition. During a routine medical examination, however, it was learned that several members of her family had died from sudden rupture of abdominal or thoracic aortic aneurysms.

On physical examination, the physician noted that she had mild hyperextensibility of joints. However, she had formerly been a gymnast without any history of joint dislocations. Also, she was negative for excessive joint laxity by the criteria of Wynne-Davies (Table I). In addition, there were no other signs of the Ehlers-Danlos syndrome in that her skin had a normal texture without unusual extensibility, ecchymoses, or abnormal scarring. She did not have a prominent venous pattern over her anterior chest or elsewhere, and she did not have a history of venous varicosities as is seen in many patients with EDS type IV $(12,13,15)$. An old appendectomy scar was well-healed. The physician also noted she had arachnodactyly. However, the hand-to-height ratio was $10.9 \%$ (Table I), the upper limit of normal. Also, she did not meet other criteria for the Marfan syndrome in that she was only 5 feet 2 inches tall, and her ratio of upper body segment to lower body segment was 0.97 , in the high normal range rather than below normal (Table I). In addition, a slit lamp examination for subluxation of the lens was negative. The remainder of the physical examination was unremarkable. An electrocardiogram and an echocardiogram were normal. A computerized tomography scan with contrast did not reveal any aneurysms in the blood supply to the central nervous system. An ultrasound examination of the abdomen did not show any dilatation of the aorta or any other abnormalities.

A more detailed medical history revealed that M.H. had frequent headaches that were apparently migraines. She also had a tendency to bruise easily, with the formation of hematomas after minor trauma. 4 yr before the examination she underwent an appendectomy and a right oophorectomy. The surgeon noted that the tissues seemed friable, they bled easily, and there was a loss of $\sim 1,000 \mathrm{ml}$ of blood. She recovered normally from the surgery. She had a 13-yr-old son and a 14-yr-old

1. Abbreviations used in this paper: EDS, Ehlers-Danlos syndrome; OI, osteogenesis imperfecta; PCR, polymerase chain reaction. 
daughter. Both were apparently in good health. The daughter had mitral valve prolapse and loose joints, but was a world-class gymnast (Table I). A slit-lamp examination of the daughter was negative.

A number of M.H.'s direct blood relatives died suddenly from vascular catastrophies (Fig. 1). Her mother (II-1) died at the age of 34 of a ruptured abdominal aortic aneurysm, and her maternal grandfather (I-2) died at the age of 55 of a ruptured thoracic aortic aneurysm. A maternal uncle (II-4) died at the age of 42 of a cerebral vascular accident. A maternal aunt (II-6) died at the age of 55 during an operation for repair of an aneurysm of the hepatic artery. A 15-yr-old cousin (III-7) died of a ruptured thoracic aortic aneurysm during a swimming competition.

None of M.H.'s direct blood relatives other than her daughter had joint laxity suggestive of EDS by the criteria of Wynne-Davis (Table I). Also, they did not have any evidence of the Marfan syndrome as judged by the ratio of upper segment-to-lower segment or by the ratio of hand length to height (Table I).

Nucleotide sequencing of $c D N A s$ and genomic DNAs. Skin fibroblasts from M.H. were grown under standard conditions (6). Total RNA was isolated from the cells (16) and used to synthesize cDNA (17) that was employed as a template for a series of PCRs (18). The PCRs were carried out with six sets of primers chosen to generate products covering all the coding sequences for the triple-helical domain of type III procollagen (10). The products of the PCR were cloned into the bacteriophage M13mp18 or mp19 and the M13 clones were used for dideoxynucleotide sequencing (19). In addition, the PCR was carried out using genomic DNA as template and two additional oligonucleotide primers. The 5'-primer was identical to sequences at the 3'-end of intervening sequence 33 and the 5 '-primer was complementary to the 5 '-end of intervening sequence 35 (9). The genomic products were also cloned into $\mathrm{M} 13 \mathrm{mp} 18$ or $\mathrm{mp} 19$ for dideoxynucleotide sequencing.

Effects of the mutation on thermal stability. To examine the consequences of the mutation on the thermal stability of the type III procollagen, cultures of skin fibroblasts from M.H. were incubated with $\left[{ }^{3} \mathrm{H}\right]$ proline for $24 \mathrm{~h} \mathrm{(6)}$. The proteins in the medium were precipitated with ammonium sulfate and dissolved in $0.4 \mathrm{M} \mathrm{NaCl} ; 0.01 \% \mathrm{NaN}_{3}$; $0.1 \mathrm{M}$ Tris- $\mathrm{HCl}$ buffer ( $\mathrm{pH}$ 7.4). Thermal unfolding of the procollagens was assayed by brief digestion with high concentrations of trypsin and chymotrypsin as described previously $(10,20)$. Samples were assayed by polyacrylamide electrophoresis in SDS without reduction.

In further experiments, ${ }^{14} \mathrm{C}$-labeled type III procollagen was purified from the medium by chromatography on two successive columns of DEAE-cellulose (6). The peak containing the type III procollagen was digested with vertebrate collagenase. The thermal unfolding of the vertebrate collagenase fragments $(21)$ was then assayed by digestion with trypsin and chymotrypsin $(10,20)$.

Detection of the mutation in saliva from living family members. To detect the mutation in the type III procollagen gene in living members of M.H.'s family, saliva samples were collected. Plastic screw-cap tubes $(50 \mathrm{ml}$ ) containing $2 \mu \mathrm{l}$ of $25 \%$ sodium azide were mailed to the individuals. Each was asked to place up to $5 \mathrm{ml}$ of saliva in the tube and
Table I. Joint and Skeletal Features of Members of the Family

\begin{tabular}{lcccc}
\hline Family member & $\begin{array}{c}\text { Joint } \\
\text { laxity* }\end{array}$ & $\begin{array}{c}\text { Ratio } \\
\text { US:LS }\end{array}$ & $\begin{array}{c}\text { Handlength: } \\
\text { height }\end{array}$ & Comments \\
\hline $\begin{array}{l}\text { Mutation positive } \\
\text { III-1 (M.H.) }\end{array}$ & & & $\%$ & \\
& & & & \\
& & 0.97 & 10.9 & $\begin{array}{c}\text { Bleeding tendency; } \\
\text { former gymnast } \\
\text { and captain in }\end{array}$ \\
IV-1 & & & & Air Force \\
& & & & World-class \\
IV-2 & $4 / 5$ & 0.92 & 11.0 & \\
II-8 & & & & \\
III-6 & $0 / 5$ & 1.05 & 11.2 & \\
Mutation negative & $2 / 5$ & 0.96 & 11.3 & \\
III-4 & & 0.94 & 8.7 & \\
III-13 & $0 / 5$ & 0.93 & 11.5 & \\
III-14 & $2 / 5$ & 1.02 & 10.7 & \\
III-15 & $1 / 5$ & 1.09 & 10.9 & \\
III-11 & $0 / 5$ & NA & 10.4 & \\
IV-7 & $0 / 5$ & 0.80 & 11.3 & \\
IV-6 & $0 / 5$ & 0.78 & 10.9 & \\
Nonblood relatives & $0 / 5$ & 0.80 & 10.1 & \\
II-7 & & & & \\
III-3 & $0 / 5$ & 1.09 & 10.1 & \\
III-5 & $0 / 5$ & 0.83 & 11.7 & \\
& $0 / 5$ & 0.98 & 11.4 & \\
\hline
\end{tabular}

* Joint laxity evaluated by criteria of Wynne-Davies (31). Excessive joint laxity is present if three of five tests are positive.

${ }^{\ddagger}$ Ratio of upper body segment (US) to lower body segment (LS). Lower body segment is measured from the top of the symphysis pubis. Normal values (13) for non-Black individuals over $10 \mathrm{yr}$ of age are $0.91 \pm 0.04$ SD. Values in 21 patients with the Marfan syndrome (13) were $0.84 \pm 0.04 \mathrm{SD}$.

$\$$ Values from randomly selected normal adults in our department: males, 10.95 $\pm 0.40 \mathrm{SD}(n=28)$; females, $10.86 \pm 0.47 \mathrm{SD}(n=26)$; combined, $10.93 \pm 0.45 \mathrm{SD}(n=54)$; combined excluding two Blacks with values of 12.26 and $11.61,10.89 \pm 0.40 \mathrm{SD}(n=52)$.

return the tube by express mail. DNA from cells in the saliva was extracted with a standard protocol (16) and ethanol precipitated. The DNA was then used for the PCR using the oligonucleotide primers for genomic DNA. The mutation destroyed a cleavage site for the restriction enzyme Ncil. Therefore, the heterozygous mutation was detected by resistance of about half of the PCR products to cleavage by NciI.

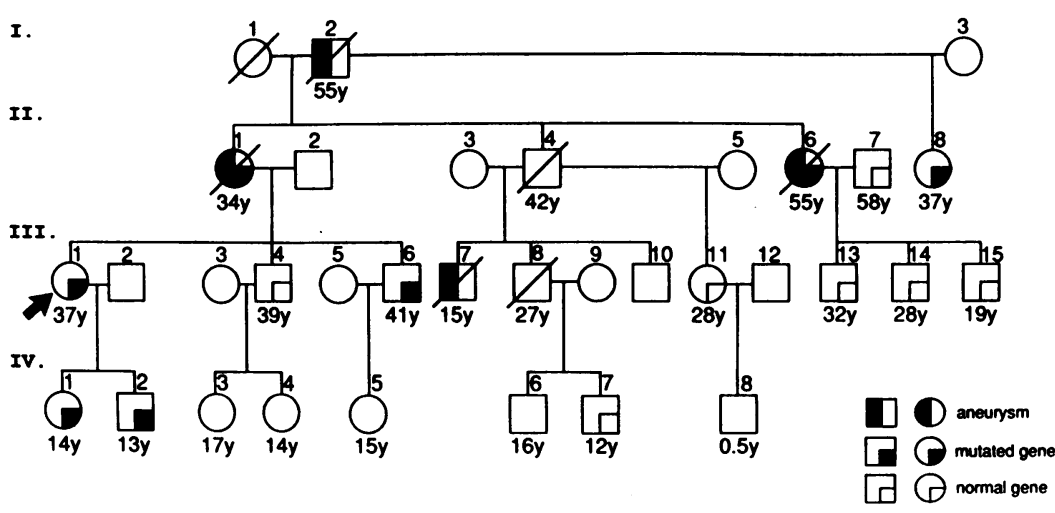

Figure 1. The family with aortic aneurysms. Arrow indicates M.H. Slashed line indicates death at the age indicated. M.H.'s maternal uncle (II-4) died at the age of 42 of a cerebral vascular accident. A cousin (III-8) died at the age of 27 of an industrial accident unrelated to any vascular disease. 
Detection of the mutation in DNA from microscopic slides and fixed tissue blocks. To detect the mutation in M.H.'s mother (II-1 in Fig. 1), DNA was extracted from a single fixed and stained microscopic slide of the aorta (Figs. 2 and 3). The slide was washed several times with $1 \mathrm{M}$ $\mathrm{HCl}$. The cover slip was freed with xylene, and the section washed extensively with xylene. The section was scraped off with a sterile scalpel into $0.5 \mathrm{ml}$ of $2 \mathrm{mg} / \mathrm{ml}$ proteinase $\mathrm{K}$ and $0.1 \%$ SDS in $50 \mathrm{mM}$ Tris- $\mathrm{HCl}$ buffer $(\mathrm{pH} 8)$. The sample was incubated at $65^{\circ} \mathrm{C}$ for $24 \mathrm{~h}$. The sample was extracted with phenol:chloroform:isoamyl alcohol (25:24:1). The aqueous phase was transferred to a new tube, and ammonium acetate was added to a final concentration of $2.5 \mathrm{M}$. Because a reddish-brown flocculant precipitate formed that was not seen with DNA from other sources, the precipitate was recovered by centrifugation and suspended in $0.5 \mathrm{ml}$ of $5 \mathrm{mg} / \mathrm{ml}$ proteinase $\mathrm{K}$ and $0.1 \%$ SDS in $50 \mathrm{mM}$ Tris- $\mathrm{HCl}$ buffer $(\mathrm{pH} 8)$ for further digestion at $65^{\circ} \mathrm{C}$ for $15 \mathrm{~h}$. $\mathrm{NaCl}$ was added to a final concentration of $0.3 \mathrm{M}$. The sample was reextracted with phenol:chloroform:isoamyl alcohol. Glycogen was added as a carrier to the aqueous phase $(60 \mu \mathrm{g} / \mathrm{ml})$ and the sample was precipitated with $70 \%$ ethanol at $-20^{\circ} \mathrm{C}$ overnight.

To detect the mutation in M.H.'s aunt (II-6 in Fig. 1), DNA was extracted from formalin-fixed and paraffin-embedded blocks (22) of cartilage and aorta. Sections were cut from the blocks with a sterile scalpel. The sections were washed with xylene. They were minced and pools of three or four sections were incubated in $0.5 \mathrm{ml} \mathrm{of} 5 \mathrm{mg} / \mathrm{ml}$ proteinase $\mathrm{K}$ and $0.1 \% \mathrm{SDS}$ in $50 \mathrm{mM}$ Tris- $\mathrm{HCl}$ buffer $(\mathrm{pH} 8)$ at $65^{\circ} \mathrm{C}$ for $24 \mathrm{~h}$. $\mathrm{NaCl}$ was added to a concentration of $0.3 \mathrm{M}$, and the sample was reextracted with phenol:chloroform:isoamyl alcohol. Carrier glycogen was added, and the DNA was precipitated with $70 \%$ ethanol. The sample was dissolved in water, ammonium acetate was added to a final concentration of $2.5 \mathrm{M}$, and the DNA reprecipitated with $70 \%$ ethanol in the presence of carrier glycogen.

To avoid contamination from DNA previously generated by PCR in the same laboratory, three different $5^{\prime}$-primers and three different 3'-primers were used to amplify DNA. The first set of primers was the same as the set used to amplify genomic DNA from M.H. (above). Two additional 5'-primers and two additional 3'-primers were external to the first set. In different experiments, the 5'-primers and 3'-primers were varied so as to synthesize PCR products not previously generated. Water blanks were consistently negative. The PCR products were then used for allele-specific hybridization (23) using oligonucleotides that were 18 mers coding for the normal sequence and 18 mers coding for the same sequence but with the single base mutation that converted the codon for glycine 619 to arginine.

\section{Results}

Pathological reports and specimens on M.H.'s mother and maternal aunt. M.H.'s mother (II-1 in Fig. 1) died in 1960. A surgical pathological report on the ruptured abdominal aorta indicated that the largest diameter was $7 \mathrm{~cm}$. The intima was yellowish in color and one portion of the aorta showed a separation of the intima from the media. Three microscopic slides of the aorta were available (Figs. 2 and 3). They demonstrated arteriosclerosis with a deposition of calcium and the presence of a blood clot adherent to the intima. There was vacuolation and marked thickening of the media. Also, there was dissection of the intima from media. No other hospital records or pathological specimens were available.

M.H.'s maternal aunt (II-6) died in 1987. She was admitted to a hospital for repair of a suspected aneurysm of the hepatic artery. At operation a 6-cm aneurysm was found in the hepatic artery. Additional aneurysms were found at the celiac axis and in the infrarenal aorta. The tissues were unusually friable and attempts to repair the aneurysms led to excessive bleeding. The patient expired in a few hours. Histology of the aorta demonstrated cystic medial necrosis underlying aneurysmal forma- tion and atherosclerosis. The past medical history indicated that she had an automobile accident $16 \mathrm{yr}$ previously with a surgical repair of a liver laceration and a splenectomy. 17 and $12 \mathrm{yr}$ previously, she underwent venous stripping of the lower extremities with venous ligation on the right on two occasions and on the left side on one occasion. $18 \mathrm{yr}$ previously, she had a repair of a cystocele and a rectocele.

A mutation in the type III procollagen gene. Total RNA from M.H.'s fibroblasts was used to prepare cDNA and the cDNA was used as a template for PCRs (Fig. 4). The PCR products were sequenced after cloning into M13. As indicated in Fig. 5, a single base mutation was found that converted the codon of -GGA- for glycine 619 to -AGA-, a codon for arginine. The mutation was found in seven of nine independent M13 clones. The other two clones had a normal sequence in the same region. To exclude the possibility of a second mutation in the coding sequences of type III procollagen, two overlapping PCR products were prepared (products 5 and 6 in Fig. 4). Because both products overlapped in sequences that included the site of the mutation, the presence or absence of the mutation was used to distinguish M13 clones with coding sequences from the two alleles. Complete nucleotide sequencing was carried out on 2,479 nucleotides in each of two clones of PCR product 5 containing the mutation. Complete nucleotide sequencing was also carried out on 2,479 nucleotides in each of two clones of PCR product 5 not containing the mutation. In addition, complete nucleotide sequencing was carried out on 1,806 nucleotides in each of two clones of PCR product 6 containing the mutation and on 1,806 nucleotides in each of two clones of PCR product 6 not containing the mutation. Analysis of the 17,140 nucleotides revealed 14 separate single base changes in addition to the mutation in the codon for glycine 619.13 of the 14 base changes were shown to be artifacts of the PCR (10) because they were not found consistently in clones containing coding sequences from the same allele. The 14th base change was a third base difference in a codon for glycine that probably was a normal variant. The results, therefore, demonstrated that the mutation that converted the codon for glycine at position 619 to a codon for arginine was the only mutation in the PCR products covering all the codons for the $\alpha$ I(III) chain (24).

To confirm the presence of the mutation in the codon for glycine 619, genomic DNA from M.H. was used as a template for PCR. The products were cloned into M13 and a total of 13 clones were sequenced. Ten had a normal sequence and three had the mutation that changed the codon for glycine 619 to a codon for arginine (not shown).

Effect of the mutation on the thermal unfolding of type III procollagen. To determine whether or not the substitution of arginine for glycine 619 influenced the functional properties of the protein, the thermal unfolding of the type III procollagen synthesized by M.H.'s fibroblasts was assayed by brief protease digestion $(10,20,21)$. The intact protein secreted into the medium had a thermal stability that was essentially the same as in control (not shown). The collagenase A fragment, containing the first 781 amino acids from the $\mathrm{NH}_{2}$-terminal end of the triple-helical domain of the protein $(9,24)$, however, had a decreased temperature for thermal unfolding compared with control type III procollagen in the same assay system (Fig. 6). The collagenase A fragment from control type III procollagen was stable to brief protease digestion up to $\sim 36^{\circ} \mathrm{C}$. The colla- 

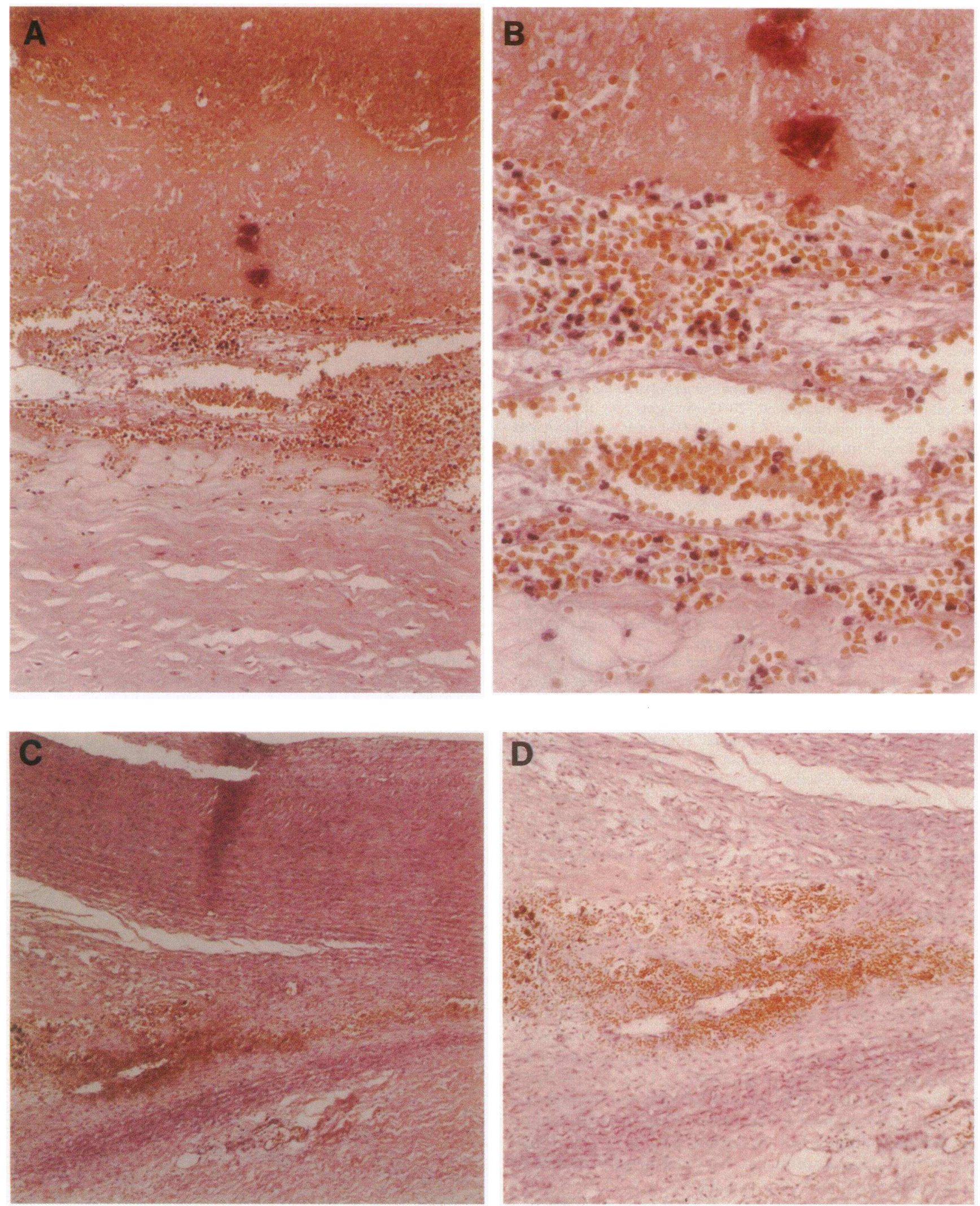

Figure 2. Photomicrographs from one of the three slides available from the aortic aneurysm found in M.H.'s mother (II-1). As indicated in text, one of the slides was used for the PCR. The specimen was stained with hematoxylineosin. $(A)$ Section through the aortic aneurysm. A recent blood clot is attached to the intima (top). The intima appears amorphous and the media (bottom) is dissected. Blood is present in the center of the medial tissue. Magnification, 143. (B) Higher magnification of the dissection in the media. Remnants of the media are shown on either side of the dissection. Amorphous structures on the top are probably artifacts in the preparation. Magnification, 380. (C) Section through another part of the aorta. The intima (top) is well organized but there is thickening of the media and bleeding into the thickened media (bottom left). The splits in the intima and media are probably artifacts from preparation. Magnification, 57. (D) Enlargement of $C$. There is some revascularization of the thickened media. Magnification, 95. 


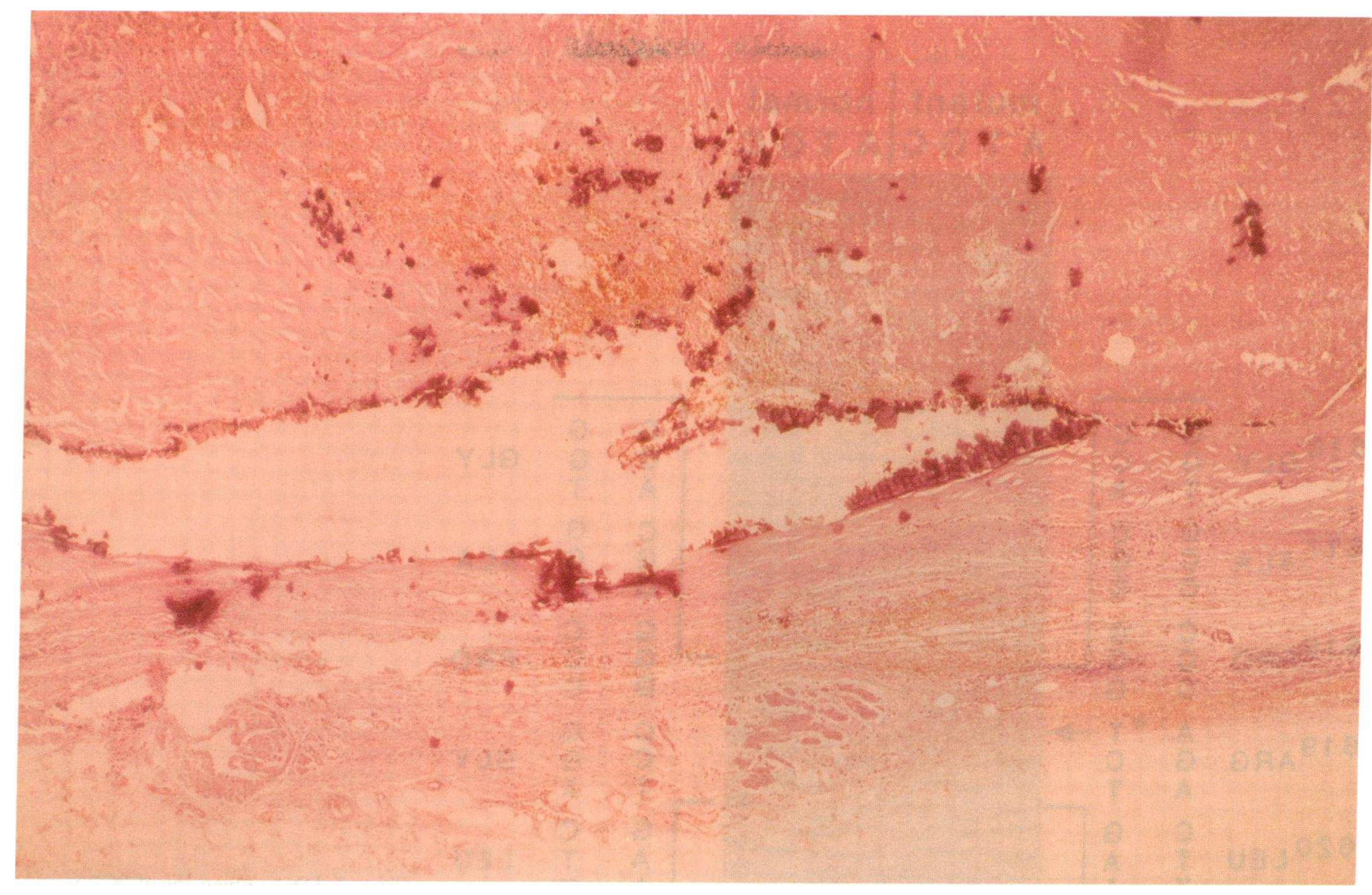

Figure 3. Microscopic section through another part of aorta from M.H.'s mother (II-1). The intima is on the top and the adventitia on the bottom. The section shows atherosclerotic changes. There are purple calcification deposits in the area of the dissection of the media. The media is disorganized. A few clear, needlelike imprints are probably remnants of cholesterol crystals that were dissolved during the preparation. Some bleeding into the boundary between the media and the adventitia is also apparent. Magnification, 50.

genase A fragment from M.H.'s type III procollagen were partially cleaved to an intermediate-sized fragment at $20-36^{\circ} \mathrm{C}$. Comparison with molecular weight standards of procollagen and collagen fragments indicated that the intermediate was $\sim 620$ residues. Therefore, the results were consistent with the presence of a glycine substitution at position 619 of the $\alpha 1$ (III) chain.

Presence of the mutation in pathological specimens from M.H.'s mother and maternal aunt. Further experiments were carried out to determine whether the same mutation in an allele for type III procollagen was found in DNA from pathological specimens from M.H.'s mother (II-1) and maternal aunt (II-6). DNA was extracted from a stained microscopic section of the mother's aorta. Also, DNA was extracted from paraffin sections (22) of the aunt's aorta and cartilage. The DNA was amplified by the PCR and used for allele-specific hybridization (23). As indicated in Fig. 7, the mutation was found in the DNA from both the mother (II-1) and the maternal aunt (II-6).

Inheritance of the mutated allele in the family. DNA in living members of the family was also examined for the presence of the mutation in type III procollagen gene. DNA was extracted from samples of saliva, and the DNA was used as a template for the PCR. Because the mutation destroyed an NciI site (-CC/CGG-), the PCR products were assayed by whether or not they were cleaved by the restriction endonuclease Ncil. As indicated in Fig. 8, the PCR products obtained using con- trol genomic DNA as a template generated fragments of 255 and $107 \mathrm{bp}$ after cleavage with Ncil. As expected, the PCR products obtained using M.H.'s DNA (III-1 in Figs. 1 and 8) generated three fragments, an uncleaved fragment of $362 \mathrm{bp}$ from the allele containing the mutation, and the two normal fragments. The results demonstrated that, as indicated in Fig. 1, both of M.H.'s children (IV-1 and IV-2) had the mutation. Also, a brother (III-6) and a half-aunt (II-8) had the mutation. The mutation was not present in six direct blood relatives (III-4, III-1 1, III-13, III-14, III-15, and IV-7). The results were confirmed by allele-specific hybridization (not shown).

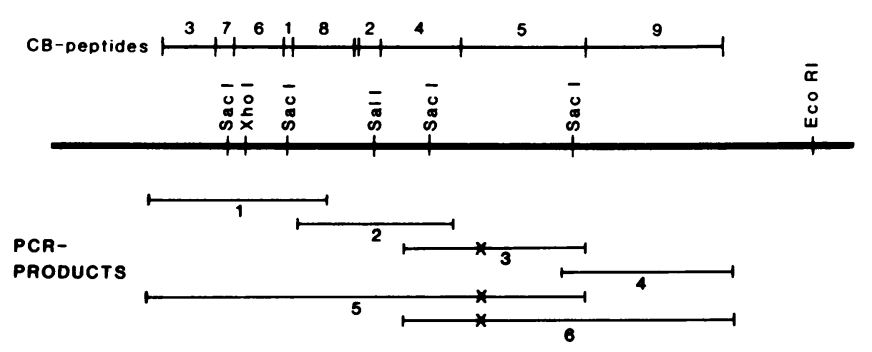

Figure 4. PCR products used for analysis of cDNAs. (Top line) $\mathrm{Cy}-$ anogen bromide peptides of the $\alpha 1$ (III) chain. (Second line) Partial restriction map of the type III cDNA. The site of the mutation that changed the codon for glycine 619 to a codon for arginine is indicated by $X$. 


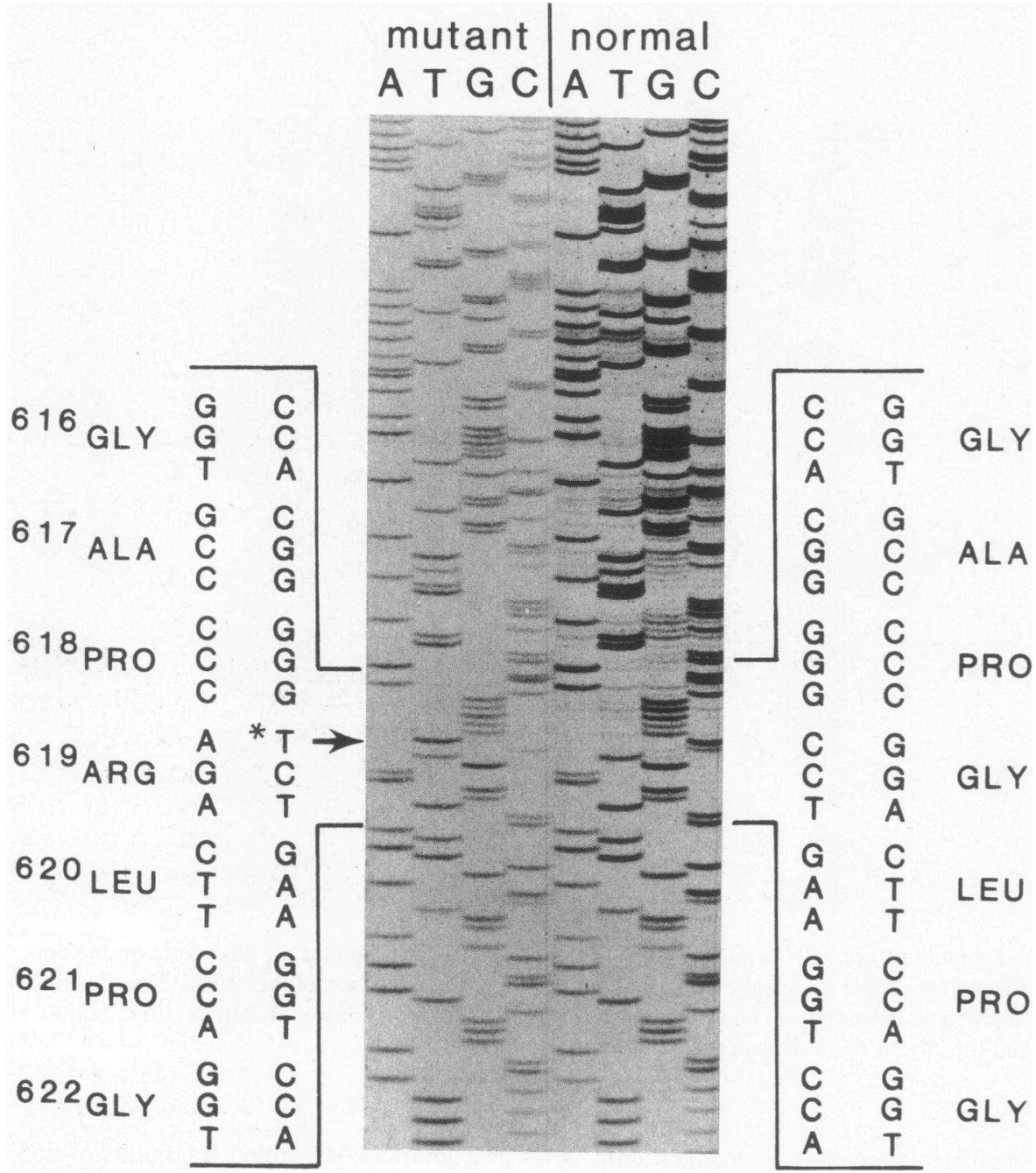

Figure 5. DNA sequencing of PCR products synthesized using cDNA as a template. The asterisk and arrow indicates the change of a $\mathrm{C}$ to $\mathrm{a} T$ in the antisense strand and, therefore, a change of a $G$ to an $A$ in the sense strand that converted the codon for glycine 691 to a codon for arginine. The sequences closest to the gel are the antisense strand.

\section{Discussion}

The family described here was identified through a 37-yr-old woman in apparent good health who was scrutinized only because many of her direct blood relatives had died of ruptured aortic aneurysms (Fig. 1). The physicians who initially examined the woman suspected a diagnosis of either the Marfan syndrome or of EDS type IV. Further evaluation of the patient, however, did not provide data consistent with either diagnosis. She was not unusually tall and her upper segment to lower segment ratio was at the upper limits of normal instead of below the normal range as is seen in individuals with the Marfan habitus (Table I). Slit-lamp examination did not reveal any subluxation of the lenses, and her handlength-to-height ratio was not consistent with arachnodactyly. Similarly, she did not have the striking skin changes that were originally cited by Beighton (12) and McKusick (13) as an important feature of the ecchymotic or type IV variant of EDS, a syndrome that is frequently associated with arterial aneurysms and rupture of other hollow organs such as the intestine. In particular, she did not have skin so thin that venous patterns were easily seen, or ecchymoses and scarring over bony prominences that are used by most authorities $(12,13,15)$ but not all $(14)$ as criteria for the diagnosis of EDS type IV. M.H. had a mild degree of joint laxity (Table I) and she said that she developed hematomas from minor trauma, but the symptoms did not prevent her from becoming first a gymnast and then an officer in the United States Air Force. One of M.H.'s relatives who died of aneurysms (II-6 in Fig. 1) had some signs and symptoms consistent with EDS type IV, i.e., rupture of medium size arteries, venous varicosities, and a history of rectocele and cystocele. As discussed elsewhere (25), there may be phenotypic overlap between the syndrome known as familial aortic aneurysms (1-4) and patients who were shown to have mutations in the type III procollagen gene and who were initially classified as EDS type IV. The most appropriate diagnosis here appears to be familial aortic aneurysms (1-4) without stigmata of any well-characterized heritable disorder of connective tissue. It will be important, however, to study more families to establish definitively the relationship between the two conditions.

Examination of cDNA and of genomic DNA from M.H. demonstrated that she was heterozygous for a single base mutation that converted the codon for glycine at position 619 of the $\alpha 1$ chain of type III procollagen to a codon for arginine. Furthermore, the mutation was shown to alter the physical properties of the type III procollagen synthesized by her fibroblasts in that the collagenase A fragment of the protein had a decreased temperature for thermal unfolding as assayed by 


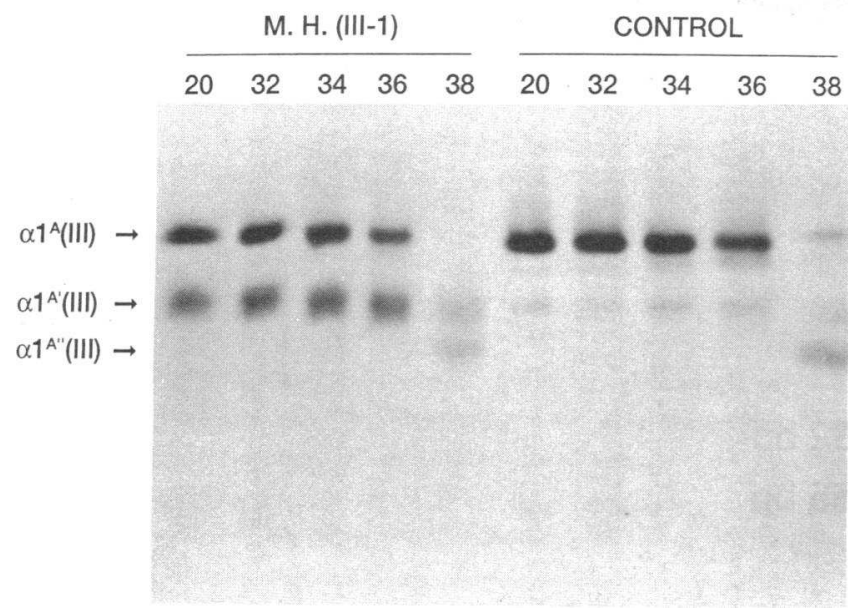

Figure 6. Thermal unfolding of type III procollagen synthesized by M.H.'s fibroblasts as tested by brief protease digestion. Type III procollagen was purified from the medium of the fibroblasts as described in the text and the thermal unfolding assayed. As indicated, a large fraction of the proband's type III collagen was digested to a fragment of intermediate size at $20-36^{\circ} \mathrm{C} . \alpha I^{A}(I I I)$, collagenase A fragment of type III collagen; $\alpha I^{A^{\prime}}(I I I)$, the intermediate fragment of $\sim 620$ amino acids; $\alpha 1^{A^{*}}(I I I)$, a second intermediate fragment of $\sim 520$ amino acids seen after digestion at $38^{\circ} \mathrm{C}$ of both the proband's and control type III procollagen.

protease digestion. In addition, the same mutation in one allele of the type III procollagen gene was present in pathological specimens from M.H.'s mother and one of M.H.'s maternal aunts, both of whom died of ruptured aortic aneurysms. Therefore, the results indicated that the mutation caused aortic aneurysms in M.H.'s family. They also indicated that she, her two children, and two of her first-degree blood relatives (Fig. 1) are predisposed to the same disease.

The mutation defined here is similar to a series of over 30 mutations in either of two structural genes for type I procollagen shown to cause OI and a few variants of the type VII form of EDS (26). Most of the mutations that cause OI or EDS are dominant, and they produce phenotypic changes that range

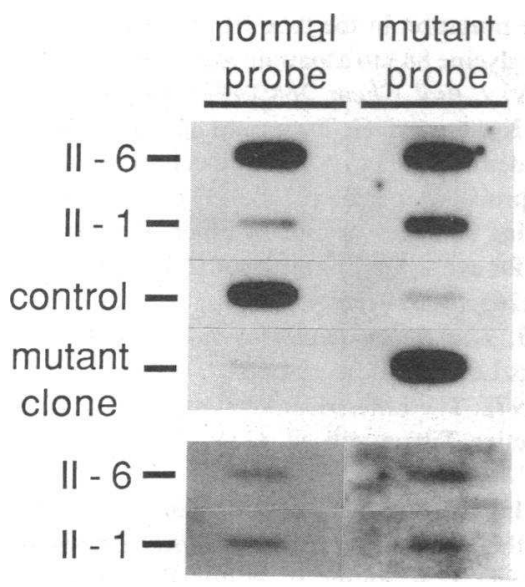

Figure 7. Allele-specific oligonucleotide hybridization of DNA from M.H.'s mother (II-1) and aunt (II-6). As described in text, DNA was extracted from pathological specimens and used as a template for the PCR. The results of two separate PCR experiments are shown. Normal probe, slot blots of the PCR products hybridized with the normal oligonucleotide; mutant probe, PCR products hybridized with the mutated oligonucleotide; control, PCR product prepared with genomic DNA from a normal individual; mutant clone, PCR product prepared with an M13 clone containing one insert of genomic DNA from the mutated allele. from mild to lethal. In large part, the deleterious effects of the mutations in the type I procollagen genes can be explained by the observation that most of them cause synthesis of structurally abnormal but partially functional pro $\alpha$ chains that are assembled into procollagen molecules. The presence of one or two abnormal pro $\alpha$ chains in the trimeric procollagen molecule interferes with folding of the protein into a stable triplehelical conformation, processing of the $\mathrm{NH}_{2}$-terminal propeptide, or assembly of the processed collagen into normal fibrils. Among the mutations causing $\mathrm{OI}$ are a series of single base mutations that alter glycine codons in the repeating -Gly-X-Ysequences of the triple-helical domain of the protein. Substitution of an amino acid with a bulkier side chain than glycine disrupts the structure of the triple helix, because a bulkier side chain cannot fit within the center of the triple helix, where the three $\alpha$ chains of the protein are in close association. One substitution of cysteine for glycine in the $\alpha 1(\mathrm{I})$ chain was shown to introduce a flexible kink into the triple helix (27) and interfere with the assembly of collagen into normal fibrils (28). Recently, several patients with EDS-IV were found to have mutations in the type III procollagen gene similar to the mutations in the type I procollagen genes found in patients with OI (7, 9-11). Two of the mutations were single base substitutions that replaced glycine residues with bulkier amino acids $(9,10)$. Both of the glycine substitutions were similar to the mutation here in that they decreased the temperature at which the triple helix of the protein unfolded.

Type I procollagen is a heterotrimer in that each molecule contains two identical pro $\alpha$ l(I) chains synthesized from one gene (COL1A1) and one similar but slightly different pro $\alpha 2(\mathrm{I})$ chain synthesized from another gene (COL1A2). In contrast, type III procollagen is a homotrimer comprised of three identical pro $\alpha$ (III) chains synthesized from a single gene (COL3A1). Therefore, a mutation that changes the primary structure encoded by one allele of the type III procollagen gene without affecting expression of the allele can alter the synthesis of the protein so that seven-eighths of the molecules contain one, two, or three mutated pro $\alpha$ (III) chains (6). However, the results here, as well as previous studies on patients with EDS type IV $(10,25)$, demonstrate that heterozygous mutations in the type III procollagen may have little if any effect on reproduction and frequently do not have serious consequences until the fourth to sixth decade. Therefore, specific mutations in the type III procollagen gene such as the mutation defined here may be relatively common among families with aortic aneurysms.

If families with aortic aneurysms have mutations in type III procollagen, the results will have important practical consequences. The mortality from ruptured abdominal aortic aneurysms is $85-95 \%$ when rupture and bleeding occur prior to surgical intervention $(29,30)$. The mortality is $<10 \%$ with elective surgery. The procedures used here make it possible to detect a mutation in a type III procollagen gene with $\sim 3$ mo of work by a skilled scientist. It is very likely that this time will be shortened in the near future. Once the mutation is detected, a simple PCR test can be carried out on saliva to determine which members of the same family have the same mutation. In most instances, the PCR test can be confirmed by a combination of digestion with a restriction endonuclease (Fig. 8) and hybridization with allele-specific oligonucleotides (Fig. 7), or by generating two overlapping PCR products that contain the 


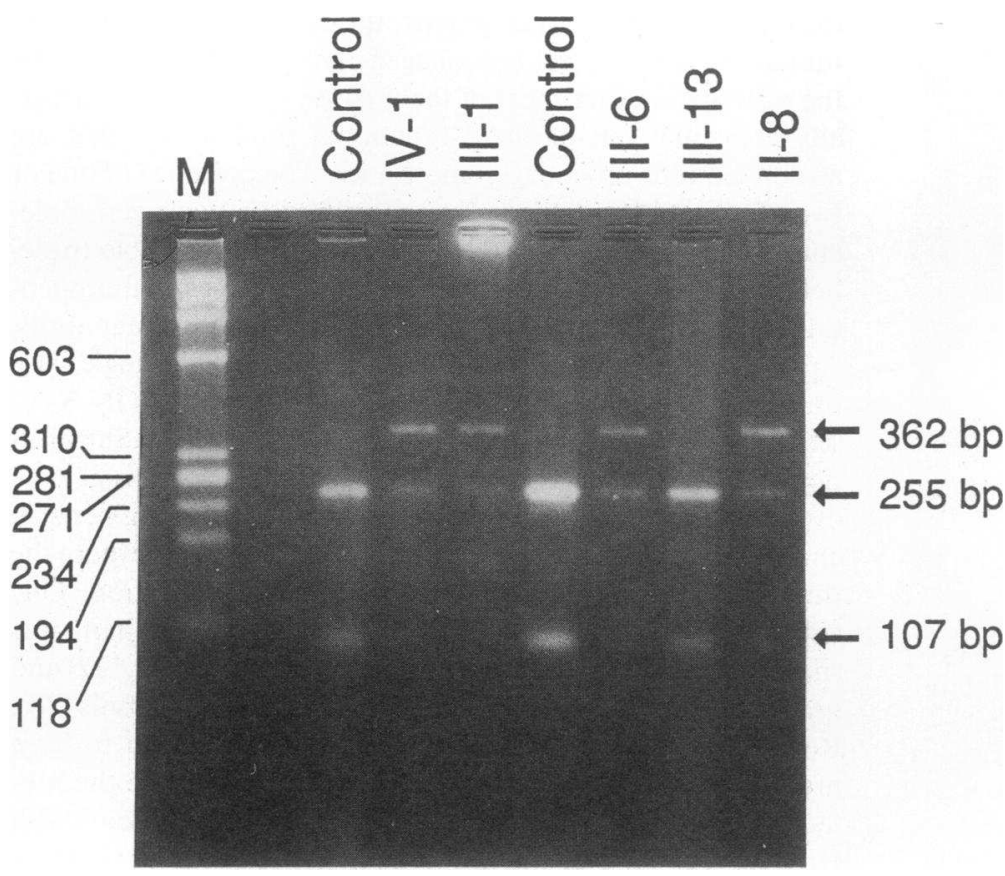

Figure 8. Detection of the mutation in PCR products from the proband and proband's family synthesized using genomic DNA from saliva. The presence of the mutation was detected by the fact that it destroys an Ncil site. Therefore, digestion of PCR products from the mutated allele revealed an undigested fragment of 362 $\mathrm{bp}$ in addition to the normal fragments of 255 and 107 bp. $M$, lane of DNA markers. site of the mutation. The affected family members can then be followed by ultrasound or other noninvasive procedures to detect aneurysms. Rupture without a detectable aneurysm can occur, particularly in individuals with classical features of EDS type IV (12-15), but surgical repair of aneurysms before rupture greatly reduces the mortality $(29,30)$.

\section{Acknowledgements}

The authors are grateful to Dr. Ronald E. Grimwood and Dr. Ramon A. Arroyo of the Lackland Air Force Base, Texas, for clinical information on M.H. They are grateful to the Department of Pathology, The Toledo Hospital, Toledo, OH, for microscopic slides from M.H.'s mother, and to Dr. Alwin D. Bennett and Dr. Andrew Britton, Department of Pathology, St. Vincent's Medical Center, Toledo, $\mathrm{OH}$, for pathological specimens from M.H.'s maternal aunt. Gi-Chung Chen and Karen Engle provided expert assistance in culturing skin fibroblasts.

This work was supported in part by National Institutes of Health Grant AR 38188 and a grant by the March of Dimes-Birth Defects Foundation.

\section{References}

1. Collin, B. R. 1985. Screening for abdominal aortic aneurysms. $J$. Surg. 72:851-852.

2. Bergqvist, D., and $H$. Bengtsson. 1986. Okat antal patienter dor av bukaortaaneurysm. Okad diagnostisk skarpa kravs. Lakartidn. 83:3010-3012.

3. Bengtsson, H., O. Norrgard, K. A. Angquist, O. Ekberg, L. Oberg, and D. Bergqvist. 1989. Ultrasonographic screening of the abdominal aorta among siblings of patients with abdominal aortic aneurysm. Br. J. Surg. 76:589-591.

4. Darling, R. C., III, D. C. Brewster, R. C. Darling, G. M. LaMuraglia, A. C. Moncure, R. P. Cambria, and W. M. Abbott. 1989. Are familial abdominal aortic aneurysms different? J. Vasc. Surg. 10:3943.

5. Pope, F. M., G. R. Martin, J. R. Lichtenstein, R. Penttinen, B. Gerson, D. W. Rowe, and V. A. McKusick. 1975. Patients with
Ehlers-Danlos syndrome type IV lack type III collagen. Proc. Natl. Acad. Sci. USA. 72:1314-1316.

6. Stolle, C. A., R. E. Pyeritz, J. C. Myers, and D. J. Prockop. 1985. Synthesis of an altered type III procollagen in a patient with type IV Ehlers-Danlos syndrome: a structural change in the $\alpha 1$ (III) chain which makes the protein more susceptible to proteinases. J. Biol. Chem. 260:1937-1944.

7. Superti-Furga, A., B. Steinmann, F. Ramirez, and P. H. Byers. 1989. Molecular defects of type III procollagen in Ehlers-Danlos syndrome type IV. Hum. Genet. 82:104-108.

8. Byers, P. H., K. A. Holbrook, G. S. Barsh, L. T. Smith, and P. Bornstein. 1981. Altered secretion of type III procollagen in a form of type IV Ehlers-Danlos syndrome. Lab. Invest. 44:336-341.

9. Tromp, G., H. Kuivaniemi, H. Shikata, and D. J. Prockop. 1989. A single base mutation that substitutes serine for glycine 790 of the $\alpha 1$ (III) chain of type III procollagen exposes an arginine and causes Ehlers-Danlos syndrome IV. J. Biol. Chem. 264:1349-1352.

10. Tromp, G., H. Kuivaniemi, C. Stolle, F. M. Pope, and D. J. Prockop. 1989. Single base mutation in the type III procollagen gene that converts the codon for glycine 883 to aspartate in a mild variant of Ehlers-Danlos syndrome IV. J. Biol. Chem. 264:19313-19317.

11. Kuivaniemi, H., S. Kontusaari, G. Tromp, M. Zhao, C. Sabol, and D. J. Prockop. 1990. Identical $\mathrm{G}^{+1}$ to A mutations in three different introns of the type III procollagen gene (COL3A1) produce different patterns of RNA splicing in three variants of Ehlers-Danlos syndrome IV: an explanation for exon skipping with some mutations and not others. J. Biol. Chem. 265:12067-12074.

12. Beighton, P. 1970. The Ehlers-Danlos Syndrome. William Heinemann Medical Books Ltd., London. 194 pp.

13. McKusick, V. A. 1972. The Ehlers-Danlos syndrome. In Heritable Disorders of Connective Tissue. 4th ed. C. V. Mosby Co., St. Louis. 292-371.

14. Byers, P. H. 1983. Inherited disorders of collagen biosynthesis: Ehlers-Danlos syndrome, the Marfan syndrome, and osteogenesis imperfecta. In Clinical Medicine. J. A. Spittel, Jr., editor. Harper \& Row Publishers, Philadelphia. 1-41.

15. Shamban, A., and J. Uitto. 1989. Hereditary diseases of connective tissue. In Textbook of Pediatric Dermatology. R. Ruiz-Maldonado, L. C. Parish, and J. M. Beare, editors. Grune \& Stratton, Inc., Philadelphia. 117-141. 
16. Maniatis, T., E. F. Fritsch, and J. Sambrook. 1982. Molecular Cloning, A Laboratory Manual. Cold Spring Harbor Laboratory, Cold Spring Harbor, NY. 545 pp.

17. Gubler, U., and B. J. Hoffman. 1983. A simple and very effcient method for generating cDNA libraries. Gene (Amst.). 25:263269.

18. Saiki, R. K., S. Scharf, F. Faloona, K. B. Mullis, G. T. Horn, H. A. Erlich, and N. Arnheim. 1985. Enzymatic amplification of $\beta$ globin genomic sequences and restriction site analysis for diagnosis of sickle cell anemia. Science (Wash. DC). 230:1350-1354.

19. Sanger, F., S. Nicklen, and A. R. Coulson. 1977. DNA sequencing with chain-terminating inhibitors. Proc. Natl. Acad. Sci. USA. 74:5463-5467.

20. Bruckner, P., E. F. Eikenberry, and D. J. Prockop. 1981. Formation of the triple helix of type I procollagen in cellulo. A kinetic model based on cis-trans isomerization of peptide bonds. Eur. J. Biochem. 118:607-613.

21. Constantinou, C. D., B. E. Vogel, J. J. Jeffrey, and D. J. Prockop. 1987. The A and B fragments of normal type I procollagen have a similar thermal stability to proteinase digestion but are selectively destabilized by structural mutations. Eur. J. Biochem. 163:247251.

22. Impraim, C. C., R. K. Saiki, H. A. Erlich, and R. L. Teplitz. 1987. Analysis of DNA extracted from formalin-fixed paraffin-embedded tissues by enzymatic amplification and hybridization with sequence-specific oligonucleotides. Biochem. Biophys. Res. Commun. 142:710-716.

23. Studencki, A. B., and R. B. Wallace. 1984. Allele-specific hybridization using oligonucleotide probes of very high specific activity. Discrimination of the human $\beta^{\mathrm{A}}$ - and $\beta^{\mathrm{S}}$-globin genes. DNA (NY). 3:7-15.

24. Ala-Kokko, L., S. Kontusaari, C. Baldwin, H. Kuivaniemi, and D. J. Prockop. 1989. Structure of cDNA clones coding for the entire prepro 1 1(III) chain of human type III procollagen: differences in pro- tein structure from type I procollagen and conservation of codon preferences. Biochem. J. 260:509-516.

25. Kontusaari, S., G. Tromp, H. Kuivaniemi, R. L. Ladda, and D. J. Prockop. 1990. Inheritance of an RNA splicing mutation $\left(\mathrm{G}^{+1 \mathrm{IVS} 20}\right)$ in the type III procollagen gene (COL3A1) in a family with aortic aneurysms and easy bruisability. Phenotypic overlap between familial arterial aneurysms and the Ehlers-Danlos syndrome type IV. Am. J. Hum. Genet. 47:112-120.

26. Prockop, D. J., C. D. Constantinou, K. E. Dombrowski, Y. Hojima, K. E. Kadler, H. Kuivaniemi, G. Tromp, and B. E. Vogel. 1989. Type I procollagen. The gene-protein system that harbors most of the mutations causing osteogenesis imperfecta and probably more common heritable disorders of connective tissue. Am. J. Med. Genet. 34:60-67.

27. Vogel, B. E., R. Doelz, K. E. Kadler, Y. Hojima, J. Engel, and D. J. Prockop. 1989. A substitution of cysteine for glycine 748 of the $\alpha 1$ chain produces a kink at this site in the procollagen I molecule and an altered $N$-proteinase cleavage site over $225 \mathrm{~nm}$ away. J. Biol. Chem. 263:19249-19255.

28. Prockop, D. J., B. E. Vogel, R. Doelz, J. Engel, Y. Hojima, and K. E. Kadler. 1989. Effects of mutations that change primary structure of collagen on the self-assembly of the protein into fibrils. Second International EBSA Symposium. Springer Ser. Biophys. 3:81-89.

29. Rutherford, R. B., and W. H. Pearce. 1988. The "difficult" abdominal aortic aneurysms: overview and initial evaluation. Semin. Vasc. Surg. 1:131-137.

30. Crawford, E. S., S. A. Saleh, J. W. Babb III, D. H. Glaeser, P. S. Vaccaro, and A. Silvers. 1981. Infrarenal abdominal aortic aneurysm: factors influencing survival after operation performed over a 25 -year period. Ann. Surg. 193:699-709.

31. Wynne-Davies, R. 1970. Acetabular dysplasia and familial joint laxity: two etiological factors in congenital dislocations of the hip. A review of 589 patients and their families. J. Bone Joint Surg. 52B:704-716. 